tions exists, so far as we know, throughout space. A view of this kind entirely gets over any difficulty of a body acting where it is not; for all bodies are everywhere, and if we consider matter to be the cause of motion of other matter, there seem; no very imperious necessity for imagining another cause which we call force.

There are two assumptions that Hertz makes which he considers can only be proved by their success. One is that all the connections in nature can be represented by linear differential equations. There are plenty of cases imaginable in which this would not be true, as, for example, connections depending on the curvature of the path. The other assumption is that forces can be represented by force functions. This, again, may not be a complete representation of nature.

Following this introduction comes the book itself, which is divided into two parts. The first part is purely kinematical, the second deals with the deductions from Hertz's fundamental postulate of motion in the straightest possible path.

The first part begins by explaining what is meant by the path of a system of points. To get at this we calculate the mean square of the displacements of a system of points when they are displaced : the square root of this, Hertz calls the displacement of the system of points. If there is a mass at each point, then the displacement of the system is the square root of the mean squares of the displacements of the points, each multiplied by the mass at it. Thus, if $s$ be the displacement of the system, and $s_{1} s_{2}, \& \mathrm{c}$., the displacements of each point of masses $m_{1} m_{2}$, \&c. Then

$$
\left(m_{1}+m_{2}+\ldots\right) s^{2}=m_{1} s_{1}^{2}+m_{2} s_{2}^{2}+\ldots .
$$

By taking $s_{1}, s_{2}, \& \mathrm{c}$, as the displacements in the element of time, we evidently get a similar expression for the velocity of the system, and for its acceleration. The mean square of the velocity of the parts of a system is well known in connection with the principle of least action. Further than this, however, Hert $z$ defines the angle between two displacements. This is defined by the equation

$$
\begin{aligned}
\left(m_{1}+m_{2}+\ldots\right. & \stackrel{.}{*}) s s^{\prime} \cos \epsilon \\
& =\left(m_{1} s_{1} s_{1}^{\prime} \cos \alpha_{1}+m_{2} s_{2} s_{2}^{\prime} \cos \alpha_{2}+\ldots .\right)
\end{aligned}
$$

$s$ and $s^{\prime}$ being the two displacements of the system as calculated above, and $s_{1} s_{1}^{\prime}, \& c$., the two displacements of each point and $\alpha_{1}, \alpha_{2}$, the angles between these latter, then $\epsilon$ is the angle between $s$ and $s^{\prime}$. Hertz remarks that these can all be very interestingly expressed in terms of space of multiple dimensions, in which analytical diagrams are supposed to be drawn. This, however, represents the real by the unattainable. There follow, then, several chapters expressing these displacements in terms of various systems of coordinates, and discussions as to the conditions that the connections of a system should fulfil in order that they may be represented by equations not involving differentials. The curvature of the path is here studied. It is defined as $c=\frac{d \epsilon}{d s}$, and from this it follows that, representing $\frac{d^{2} x}{d s^{2}}$ by $x^{\prime \prime}, \& c$.

$$
\left(m_{1}+m_{2}+\ldots\right) c^{2}=\Sigma_{1}{ }^{1}\left(m_{1} x_{1}{ }^{\prime 2}+y_{1}{ }^{\prime \prime 2}+z_{1}{ }^{\prime \prime 2}\right) .
$$

The problem then of making the path of the system straightest, is to make $c$ a minimum consistently with the connections of the system. Now, in accordance with his assumption that the connections of the system are linear differential equations of the form

$$
\mathrm{z}_{1}{ }^{1} \mathrm{P}_{1} x_{1}^{\prime}=0 \text {, }
$$

whose differentiation gives

$$
\Sigma_{1}^{1} \mathrm{P}_{1} x_{1}^{\prime}+\Sigma^{1} \Sigma_{1}^{1} \cdot \frac{d \mathrm{P}_{1}}{d x_{2}} x_{1}^{\prime} x_{2}^{\prime}=0,
$$

we are to determine the minimum value of

when

$$
c^{2}=\Sigma_{1}{ }^{{ }^{2} \frac{m_{1}}{m}} \cdot x^{\prime \prime}{ }_{1}^{2},
$$

$$
m=m_{1}+m_{2}+\ldots \ldots
$$

In determining the variations of these, we must recollect that the positions and direction of displacement, i.e. the first differentials of the system, are supposed given, and that it is only the second differentials that can be varied in order to make $c$ a minimum. Calling, then, a system of indeterminate co- efficient $\lambda, \mu, \&$ c., corresponding to the equations of condition, we evidently get a system of equations of the form

$$
\frac{m}{m} x_{1}^{\prime \prime}+\Sigma_{1}{ }^{1} \mathrm{P}_{1} \lambda=0,
$$

which are sufficient to determine the second differentials re. quired.

From this form of result one can see how the ordinary equations of motion are derivable from the conception of the straightest path, and how, when dealing with part of a system, these indeterminate coefficients introduce what are equivalent to forces. This method of deducing the equations of motion lends itself particularly well to the deduction of the principles of least action, and the other general methods in dynamics. So far, he deals with free systems subject only to internal constraints. It is where he investigates how to deal with parts of systems that he requires to consider the nature of the constraints joining one part to another. For this purpose he defines two systems as coupled when coordinates can be so chosen that one or more of them are the same for both systems. Force is then defined as the action one system has on another. Now, when a coordinate is the same for two systems, one of the equations of condition is $\dot{p}=\bar{p}^{\prime}, p$ and $p^{\prime}$ being coordinates of the coupled systems, and for this equation the coefficient $P$ becomes the same in the two systems, being unity for each, so that the equations of motion involve the indeterminate coefficient $\lambda$ corresponding to this equation equally with reference to each system. It is thns that the equality of action and reaction appears, being thus bound up with the constant equality of the common coordinate. This seems to be where the assumption that the connections are rigid is introduced. When rigid bodies act upon one another by non-slipping contact, certainly the coordinates of the point of contact are common to the two systems. It is also quite evident that if we assume rigid bodies acting upon one another by contact only, we can have no potential energy, and all necessity for talking about the forces disappears. In Hertz's system there are no forces like Newton's acting between bodies which have no common coordinate, like the earth and the sun. We would have to invent connections to explain the motion before we could be certain that action and reaction are equal in this case.

The proof of the principle of virtual velocities by substituting for the forces between parts of a system a number of pulleys which produce the same effects, is quite analogous to Hertz's supposition that the actual connections are by rigid bodies. It is not, however, liable to the objection that the connections may become tangled, for it is only applied to the case of infinitesimal virtual displacements, while Hertz postulates the possibility of his connections existing as the real ones for all time, and throughout all finite displacements of the system.

The work considers many other matters, and shows how all the general methods in dynamics are deducible from his funda. mental postulate of the straightest path. It includes discussions on how best to deal with systems whose connections do not involve differentıals, how to treat cyclical coordinates, and many other matters. It is most philosophical and condensed, and gives one of the most-if not the most-philosophical presentations of dynamics that has been published. It is worthy of its author: what more can be said? G. F. FITZGERALD.

\section{PSEUDO-SATELLITES OF JUPITER IN THE SEVENTEENTH CENTURY.}

IN the New York Nation for January II, I894, Dr. D. C. Gilman, President of the Johns Hopkins University, called attention to an interesting letter from John Winthrop, jun., to Sir Robert Moray, concerning the satellites of Jupiter. In this letter, which was written from Hartford, Connecticut, on January $27,166 \frac{4}{3}$, Winthrop described an observation of Jupiter which he had made on the night of the previous 6th of August, when he had very distinctly seen five satellites about that planet. He was naturally " not with out some consideration whether that fifth might not be some fixt star with which Jupiter might at that tyme be in neare conjunction," and expressed the wish that more frequent observations might be made upon that planet with a view to ascertaining whether it is not impossible to discern a fixed star, when it is so near to the planet as to appear "within the periphery of that single intuitus by a tube which taketh in the body of Jupiter," and if

No. 13 I6, voL. 5 I ] 
so, whether his star is not a new satellite. He further proceeds :- "I am bold the rather to mention this as an inquiry whether any such number of Satellites or moons hath beene seene by your honor or Mr. Rooke [? Hooke] or any mathematitians or other gentlemen that have good tubes and often have the curiosity to view the planet, for possibly it may be new to me which hath beene more usually knowne by others, though the notion of such a thinge is not new to my selfe, for I remember I mett with the like narration many years since in a little booke intituled Philosophia Naturalis per Joh. Phociliden, though then I thought that was but a mistake of some fixed starrs." Now that Prof. Barnard has discovered a genuine fifth satellite of Jupiter after the lapse of nearly three centuries since Galileo's telescope detected the Medicean stars, a greater interest is given to those imaginary satellites which from time to time have claimed a place in the solar system. In a paper in the Johns Hopkins University Circular for last May (referred to in Nature, vol. 1. No. I283, p. I I3), Mr. Frank H. Clutz has given a probable identification of Winthrop's supposed satellite with B.A.C. 6448 . In a postscript to his article it is pointed out that the work to which Winthrop refers is presumably the "Philosophia Naturalis, seu Physica Vetus-Nova" of Johann Fokkens (born at Holwarden in Friesland in 1618 ; died at Franeker, February 19, I651). At President Gilman's sugges. $\mathrm{ti} n$, I have followed up this clue, and have succeeded in examining the work in question. I find that it contains more than a casual reference to additional satellites of Jupiter; in fact, a whole chapter is devoted to a discussion of certain observations, which seems to be sufficiently interesting to deserve a hrief notice.

Phocylides' treatise was published at Franeker in 1651, shortiy after the death of the author. On the title-page it is described as written "Ab Eximio Viro/JoH. Phocylide Holwarda/ L.A.M. Med. Doct. \& Philosophiæ,/dum viveret, Profess. Ordinario." There is also a portrait. The third of the three parts into which the book is divided is entitled "Physica Cœlestis," and it is doubtless this portion of the Philosophia which Winthrop had in mind when writing his letter to Sir Robert Moray. It is not Phocylides himself who claims to have discovered new moons of Jupiter; nor does he believe in their existence. On the contrary, he treats the supposed observations with the severest disapprobation; and while in general he is enthusiastic over the revelations which the telescope had already made and was daily making, this particular discovery, which he regards as spurious, rouses him to the most strenuous exertions in order to effect its refutation. The discoverer, by name Antonius Maria Schyrleus de Rheita, stated that he had seen, not one, but five new satellites of Jupiter, all farther removed from the planet than the four Galilean m sons, and revolving in a contrary direction. Phocylide, account of the matter may be briefly summarised as follows: First he refers to five stars near a certain known star of the four h maunitude. They are "intra duodecimum \& decinum quintum Piscium gradum" (p. 205) "versus sinistram secundum Signorum successionem." (p. 205 and p. 284.)

These stars, he continues, have given rise to no little controversy among learned and experienced astronomers (astrophilos' whether they are fixed stars or erratic, and, more particularly, whether they are companions (commilitones) of Jupiter. The discussion of this point is then postponed. Chapter xvi. treats of the number of the planets and their division in kind. Both satellites and planets proper are in cluded in the term "planetæ." After rejecting the sun from his ancient place among the seven planets, and adding to their number the two laterones ahout Saturn and the four about Jupiter, discovered in the "current century by the aid of new and admirable instruments, such as Tubi Optic', specula, and others of the same sort," he adds the Earth to the twelve hitherto obtained. It is thus certain, he says, that there are at least thirtern planets, since it is not yet known whelher Mars, Venus, and Mercury have any laterones rev llving an out them. "But as to the five other circumjuviales which P. Anion. Mar. de Rheilâ toasts that he has ubserved and called Urban Ocıavianæ, learned men are justly in doubt whether they should be referred to the fixed or to the wardering stars." Nothing further is added at this place, but he proceed to divide the thirteen planess into primary and secondary. The former (six in number) are named in order from Mercury to Saturn, with the Earth in the Sun's former place. I he latter are Saturn's two, and Jupiter's f.ur satellites. The seventh is the Moon. Anyone who doubts this, he adds, will be couvinced by what is soon to be said, as well as by the considerations contained in the chapter "De Lunæ corpore \& motu." After several interesting chapters, including one on Saturn and his laterones, and another on Jupiter and the Medicean stars, we come to chapter xxi., entitled "De Pseudo-Jovialibus : \& priorum consectaria." Phocylides' attitude is at once disclosed. He refers to the pseudo-discoverer as "quidam Antonius M iria de Rheita, (homo in Papatu arrogans, invidus, judicio præceps \& fatuus, aliorum gloriam pro propriâ injustè \& cuin pudoris oblivione captans \& vindicans)."

The discovery was alleged to have been made at Cologne near the end of the year 1642 , and was announced in a letter to Puteanus. But it so happened that Hevelius had noticed and described these very stars several months previously. His observations were made in August 1642 and the succeeding $\mathrm{m}: \mathrm{nths}$, and Phocylides regards the claims of Rheita to have been the first to discover them as "fœtidum mendacium," as, by his own admission, be did not obverve them before the end of the year. The identity of Rheita's pieudo joviales with these fixed stars is shown by a comparison of the actual positions of Jupiter on the dates when the observations were made. Our author poin's out that on December 29, the day of Rheita's discovery, Jupiter occupied the same position as on the previous $4^{\text {th }}$ of Sep ember, when Hevelius observed him and noticed the five stars. This position is defined by Phocylides in the words, "decimo tertio gradu Piscium, cum quindecem minutis." Again, Hevelius saw Jupiter on August 28 " in decimo quarto gradu Piscium, cum quindeceın minutis," where Rheita observed hım on January 4 of the following year (16+3). The new circum-:oviales are then, says Phocylides, none other than the stars recently discovered in Aquarius. They do not move round Jupiter, as they would do if they were secondary planets, and are therefore fixed stars, "manebuntque [fxæ] usque ad sæculi consummationem." They were observed by Hevelius to remain stationary, while Jupiter left them behind him. Phocylides challenges any doutiter to look for these stars himself, when all five will be found in their original position and at the same distances one from another. He concludes with the words (p. 289): "Hallucinatur itaque cra-sè \& inani nimı slor o â Rheita se ipsum uttllat."

Tne following will thiow furcher lizht on Rheita's tendency to form hasty conclusions. According to Phocylides he declared that he had observed three of the Medicean stars to be in a straight line, but the fourth "tantam obtinuisse latitudinem, quæ, si ex centro Jovis Eccentricum ad illum excurrentem metiamur, ad quindecem gradus excrescat." This, says our author, is contradictory to the observations of all " "nathematicians," who unanim usly agree that the Medicean stars never recede from Jupiter in latitude more than three minutes, whether to the north or to the south. He then states that this fourth star, so far from being a true Galilean satellite, was not even a pseudo-jovial, but another fixed star. Gasiendi observed the satellites on the same night, and saw all four in a straight line, the second lightly to the north; but they were differently dis osed with regard to Jupiter. In all probability, Phocylides concludes, the first (innermost) satellite was obscured by the planet, if, as is likely, the ohservations were nut made at precisely the same hour; for Jovial Mercury (as he is called) runs his course round Jupiter in a few hours more than a whole day. Pnocylides supposes that, as Rheita was well aware that there wer-four satellites, he mistook this fixed star for the fourth satellite.

The existence of Rheita's new satellites was opposed by, Gassendi in his "Judicıum de novem stellis circa Jovem visis" (see Drlambre, "His. de l'Ast. Mod.," ii. p. 35 I), and by Hevelius in his "Selenographia," ib. p. 437). Lobkowitziu; defended Rheita against Gaisendi ("Ph icylides," p. 295). Delambre devotes several payes to Rheira, or Schyrle, ani giv s some account of hi; work "Oculus Enoch et Elis., sive Radius sidereomystıcus," Antwerp, I645. In this book, according to Delambre, he admits that he has not succeeded in observing his satellites again, but asserts anew that he noticed changes in their mulual distances. He explains their disappearance by connec ing them with variable stars, which he supposes to have large orbits and long revolutions. He believed, moreover, that the spots of the suns were planets, and that the sun itself rotated wut once in a year.

Phocylides also mentions circum-mariales and circum. saturnales, which, no less than the circum-joviales, must be held to be fixed stars.

It will thus be seen that Wintlurop was right in remembering NO. I 310 , VOL. 51$]$ 
Phocylides' treatise as a work in which the discovery of new satellites was mentioned. But apparently he did not remember very accurately the position assumed by the author, for the book contains but little to encourage an observer in the belief that he has discovered new satellites.

It is perhaps worth noticing that the Philosophia was published less than fourteen years before the date of Winthrop's letter; it must therefore have been quite a new book when Winthrop perused it, as he says, "many years since."

Charles W. L. Johnson.

\section{UNIVERSITY AND EDUCATIONAL} INTELLIGENCE.

OXFORD.-Prof. J. Burdon Sanderson has been appointed Regius Professor of Medicine in succession to Sir Henry W. Acland, whose resignation $w$ as announced last Term. In accenting the Regius Profeseorship, Prof. Sanderson vacates the Waynflete Chair of Physiology, which is more valuable in a pecuniary sense. It is naturally a matter of regret that he should formally sever his connection with the school of Physiology which he may be said to have created in Oxford, but it is recognised that no better appointment could have been made to the headship of the Medical School which he has done so much to encourage, and whose interests he will have further opportunities of promoting in his new position.

At a meeting of the Royal Statistical Society held on Tuesday, a paper was read, by Mr. L. L. Price, on "The Colleges of Oxford and Agricultural Depression." The accounts of the Oxford and Cambridge Colleges have been published year by year for some time pa-t, and in Mr. Price's paper the accounts of the Oxford Colleges for the years 1 883-93 were brought under review. The gross external receipts of the Colleges were in 1893 some 611 ,oco less than in 1883 , and the $n \in t$ external receipts some $f, 13,000$. Though the external receipts are not entirely derived from agricultural estates, it seems within the facts to regard agricultural depression as responsible for a loss of upwards of $£ 60,000$ of income in 1893 . Turning to the effects of the depression upon the emoluments of the Heads, Fellows, Scholars, and Exhibitioners, to which the College revenues are mainly devoted, it appears that these effects have been mitigated hy the circum. stances that the external receipts are not exclusively agricultural, and that the emoluments are also partly derived from internal receipts and from Trusts. Still the emoluments of the Heads have tallen from $£ 22,811$ to $£ 20,905$, and of the Fellows from $£ 83,820$ to $£ 74,749$. The emoluments of the Scholars and Exhibitioners have however increased from $\& 44,776$ to $£ 48,378$. and their number has grown by upwards of ninety; and if the increast contributions made by the Colleges to the Uriversity are taken into consideration, the fall in the total payments is only about 5 per cent. But there are Colleges, where diminutious bave occurred of more than 25 per cent. in the emoluments of the Fellows, and the figures generally are altered con-iderably for the worse by eliminating a few prosperous Colleges.

CAMBRIDGe.-Mr. A. Hutchinson, Fellow of Pembroke College, has been appointed Demonstrator of Mineralogy and Assistant-Curator of the Museuw, in place of Mr. Sully, who has retired.

The Downing Professor of Medicine (Dr. Bradbury) announces that the newly-organised Museum of Materia Medica and the Pharmacological Laboratory are now open daily to students of medicine, and that demonstrations will be given therein by Mr. Marhall, the assistant to the Professor.

Dr. Gaskell, F.R.S., has been appointed an additional member of the Board for Biology and Geology.

The Royal Agricultural Society has now issued its revised regulations and syllabus for the society's senior examinations, framed in accordance wilh the important modifications recently decided upon. The council have resolved to place annually at the disposal of their education commitree five lite memberships of the society, to be awarded to the five candidater who stand highest on the list of winners of first-class certificates, and who obtain not less than two-thirds of the maximum number of marks. The gold medal of the society will be bestowed upon the candidate who :tands highest on the list of winners of life memberships, provided that he has obtained not less than threefourths of the maximum number of marks, and silver medals upon the other winners of life memberships, including the candidate at the head of the list, if he does not reach the standard required for a gold medal.

THE Association of Head Masters held its first meeting as an incurporated body on Thursday last. One of the items of the agenda was a paper in which Mr Stuart described the usual practice of teacbing science, and said most of them were satisfied that such a system had no educational value at all. All experiments must be capable of being performed and the observations made by the students. The experiments must be chiefly quantitative and especially at first. Books and lecture demonstrations must be avoided. He thought that a good groundıng in science might be given by doing practical work in an ordinary class-room, upon common tables, with home-made apparatus. The following resolutions were afterwards passed by the meeting :-

(a) "That the association is of opinion that examining bodies should encourage a more rational method of teaching science, by framing the syllabuses in such a manner that the practical work required may be strictly illustrative of the theoretical instruction given."

(b) "That it be referred to the general committee to appoint a small sub-committee, so that a report may be presented to the next summer general meeting containing detailed suggestions which it is proposed to make to examining bodies concerning examinations in science."

THE Research Scholarship given by her Majesty's Commissioners for the Exhibition of $\mathbf{1 8 5} \mathbf{I}$, to Mr. Edward Taylor Jones, of the University College of North Wales, in 1892, has been renewed for a hird year. Such renewal is only made in cases of exceptional merit, where valuable scientific results are likely to be obtained by a continuance of the scholar's research work. Mr. Jones has just completed, at the University of Berlin, an experimental investigation solving an important problem in magnetism. An account of the research has been communicat ed to her Majesty's Commissioners, and will shortly be published.

THE P'rofessorship of Mathematics in the Government Training College, Ireland, vacant by the retirement of Principal Corbett, has heen filled by the appointment of Mr. Dilworth, of Trınity College, Dublin.

\section{SOCIETIES AND ACADEMIES. \\ PARIS.}

Academy of Sciences, January 7.-M. Marey in the chair. - A list of the present members, foreign associates, and correspondents of the Academy is given.-M. A. Cornu was elecred Vice-President fur 1895 - Pre iaration, in the electric furnace, of graphites foisonnants, by M. Henri Moissan. For all varieties of graphite prepared by intense heat, the temperature of intumescence after siaking in nitric acid is about $165^{\circ}-175^{\circ} \mathrm{C}$. They resemble natural graphites in this and other respects, hence the probability that the latter have been produced at a very high temperature under moderate pressures in masses of iron which have since disappeared, - The vasomotor nerves of the veins, by M. L. Ranvier. From the results of experiments quoted, the author concludes that veins as well as arteries are supplitd with vasomotor nerves. - On the first scientific voyages of the Princess Alice, by Prince Albert I. of Monaco.-An addition to Le Veırier's theory of the movement of Saturn and rectification of the Tables, by M. A. Gaillot.On the approximate development of the perturbation tunction, by $M$. N. Coculesco. - On roots common to several equations, by $M$. Waliher Dyck. - On the theory of a system of ditferential equar ions, by M. A. J. Stodolkievitz.-On the theory of exchangeable substitutions, by M. Demeczky. - On the absolute value of the magnetic elements on January I, I895, by M. Th. Moureaux. The values are given for (A) Parc Salul-Maur, Long. $0^{\circ} 9^{\prime} 23^{\prime \prime}$ E. and Lat. $48^{\circ} 48^{\prime} 34^{\prime \prime} \mathrm{N}$. ; (B) Perpignan, Long. $0^{\circ} 32^{\prime} 45^{\prime \prime} \mathrm{E}$. and Lat. $42^{\circ} 42^{\prime} 8^{\prime} \mathrm{N}$.

Elements. Abs. values Jan. $x, 1895$. Secular variation in 1894 .

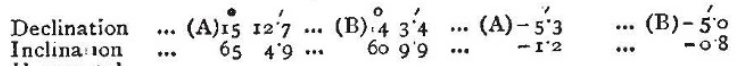

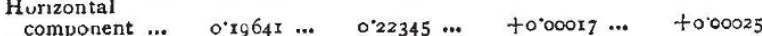

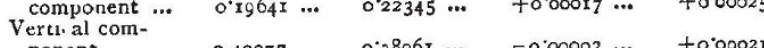

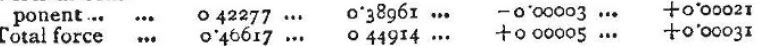

